\title{
Theory of Mind and Neurodevelopmental Disorders of Childhood
}

\author{
BARIS KORKMAZ
}

Department of Neurology, Division of Child Neurology, Istanbul University, 34301 Istanbul, Turkey

\begin{abstract}
To a large extent, the human infant is socialized through the acquisition of a specific cognitive mechanism known as theory of mind (ToM), a term which is currently used to explain a related set of intellectual abilities that enable us to understand that others have beliefs, desires, plans, hopes, information, and intentions that may differ from our own. Various neurodevelopmental disorders, such as autism spectrum disorders, attention deficit hyperactivity disorder, developmental language disorders, and schizophrenia, as well as acquired disorders of the right brain (and traumatic brain injury) impair ToM. ToM is a composite function, which involves memory, joint attention, complex perceptual recognition (such as face and gaze processing), language, executive functions (such as tracking of intentions and goals and moral reasoning), emotion processing-recognition, empathy, and imitation. Hence, ToM development is dependent on the maturation of several brain systems and is shaped by parenting, social relations, training, and education; thus, it is an example of the dense interaction that occurs between brain development and (social) environment. (Pediatr Res 69: 101R108R, 2011)
\end{abstract}

$\mathrm{H}$ uman beings continuously make inferences about the psychological states of others. Each of us is constantly analyzing our impressions of others and constructing theories on the basis of the cues and information we receive. This enables us to understand ourselves and others and is a key determinant of self-organization and affect regulation. In addition to "verbal" descriptions of people and observation of their actions, the individual seeks deeper, more psychologically meaningful understandings and attributions in a causal framework to explain and to predict others' behavior on the basis of internal mental states (1). This kind of theory construction that makes up the core of everyday (folk) psychology is known as Theory of Mind (ToM), a term originating from a study of chimpanzee behavior (2), but entails verbal and conceptual abilities.

ToM, mindreading in everyday parlance (3), is one of the subcomponents of social cognition, which embraces all the skills required to manage social communication and relationships in humans and nonhumans. It develops on the basis of certain mentalizing mechanisms and cognitive abilities and gives rise to the awareness that others have a mind with various mental states including beliefs, intuitions, plans, emotions, information, desires, and intentions and that these may differ from one's own. Impairment of ToM ability is often

Received October 27, 2010; accepted January 5, 2011

Correspondence: Baris Korkmaz, M.D., Division of Child Neurology, Department of Neurology, Cerrahpasa Medical Faculty, Kocamustafapasa 34301 Istanbul, Turkey; e-mail: bkorkmaz@istanbul.edu.tr seen in children with autism, even in cases with a normal or high level of intelligence and other cognitive abilities (4).

ToM develops fully only in human beings; the presence of a rudimentary ToM in some nonhuman primates and other animals is arguable although they can show very complex social behavior (5). The evolution of ToM probably depends on the increased size of the neocortex and increased importance of vision in primates as well as human beings' complex forms of social organization (6).

\section{Developmental Precursors of ToM}

Normally developing children attain ToM at roughly 3-4 y through a progression of stages starting at around 18 mo with the awareness that their own mental states are distinct from those of others $(4,5,7)$.

The precursors of ToM development include forms of nonverbal communication and gnostic functions that begin to function at birth, for example, physical and emotional contact between mother and child involving reciprocity, engagement, empathy, and imitation. Empathy refers to intuitive and emotional awareness of others' feelings, the consequence of which is identification and compassion. While empathy is an emotional reaction that is appropriate to another person's mental state, ToM is a more complex cognitive ability, one of whose components is grasping the other person's perspective (8).

Perceiving faces, distinguishing between the mother's face and unfamiliar ones, and recognizing facial emotions and expressions are vital for the development of the perceptual components of ToM. From the very beginning of life, the natural and cultural development of the child merge into each other in such a way (9) that perception becomes social perception - the basic neuropsychological function-and opens the door to ToM development. In fact, recent studies demonstrate that the neural mechanisms supporting basic sensory processing of social information and the theory-of-mind system have an interactive bidirectional relationship (10). Looking, smiling, and smiling back - the first examples of inborn social behavior that appear-are perhaps evidence of an empathic sense of reciprocity between mother and child (11). The child integrates all the information coming from different senses: facial expressions, prosodic differences in the voice of its mother as well as her touch and smell, so as to correspond

Abbreviations: ADHD, attention deficit hyperactivity disorder; ASD, autism spectrum disorder; EF, executive functions; MPFC, medial prefrontal cortex; ToM, theory of mind 
to the accompanying feeling the mother is expressing. One of the critical stages of ToM development is distinguishing direct from averted gaze, which is the basis for referential gaze perception and communication. Although children can distinguish direct and averted gaze motion at a younger age $(12,13)$, they cannot make explicit judgments of direct gaze and certain inferences until the age of 3 or 4 (14).

Joint attention, which occurs in all sensory modalities, is a shared attention to goal-directed and intentional action. It is present as young as 3 mo (15) but becomes a refined mechanism between the ages of 9 and 18 mo. The recognition of the intentional action of agents-separation of means and ends-is essential for the development of joint action. At 18 mo, children show clear signs of sensitivity to others' intentions (3). On the other hand, gestures, which sometimes replace verbal language as an effective means of communication between people, play an important role in the development of joint attention. One especially important gesture is pointing, which normally develops between the ages of 9 and 14 mo, after which other conventionally significant gestures appear. Whether the child points to direct the caregiver's attention to something that might be out of reach or the child looks in the direction of the caregiver's pointing finger as a way to initiate joint attention, pointing is one of the major milestones in ToM development (16).

The ToM system probably starts to operate in the human from about $13-15$ mo of age $(4,17,18)$ at the time when language learning takes place rapidly. At 18-24 mo, convergence of several important developmental milestones, such as true understanding of joint attention, deliberate imitation, and the ability to track a speaker's intention during learning and decoding of words, occurs.

Pretend (make believe) play, which includes "joint proposals," "role assignment," and "metacommunication about a scenario" significantly facilitate ToM development (19). Substituting imaginary situations for real ones, the child begins pretend play around the age of $18 \mathrm{mo}$, initially prompted by adults, who encourage children to take part in pretend scenarios. Pretend play declines after $6 \mathrm{y}$. It is one of the areas of development that is most intensely affected in autism (20).

\section{Theory of Mind}

On the basis of precursors and the incorporation of several other neuropsychological functions, children's social interactions (with peers and adults) triggers and promotes spontaneous development of ToM around the age of 3-4 without any formal instruction or overt effort. The distinction between mental and physical appear first so that the child conceives that mental phenomena are abstract, subjective, and intangible, whereas physical objects and overt behaviors are concrete, visible, and manifest (3). Second, commonsense notions of psychological causality develop, e.g. "When somebody receives a present, they feel happy"; hence, children understand that mental phenomena are states-with-contents as causes of behavior (21). They understand why people feel a certain way and notice others' motives and learn to induce some mental states. They realize that the same world can be experienced in different ways by different people and infer from gaze direction what a person is thinking or what a person might want. They explain events by attributing them to unobservable entities, such as beliefs or desires. One of the essential features of ToM, which basically depends on "emotion cognition," is false-belief understanding; therefore, concepts of belief, desire, and pretend form the core of the ToM framework (21).

Development of ToM depends largely on the normal functioning of memory systems including short-term and longterm declarative memory, source memory, and different forms of implicit memory including emotional memory. Although the age interval of ToM development roughly coincides with that of the development of autobiographical memory (22), recent studies indicate ToM functioning is partly independent of episodic memory (23). However, a certain minimum working memory capacity is required to develop a ToM as children cannot frame concepts about others' minds until they are capable of contemporarily keeping in mind different perspectives of thoughts. The ability to simultaneously take into account the real situation and the pretend version of the same situation to shift between external events and internal representations emerges between 18 and 24 mo (24), and after this time, children are able to manipulate the information held in memory: realizing that their own thoughts may not be known by others, they can freely compare and contrast different lines of thought.

Language is indispensable for the development of ToM because without language there can be no theory. Early language development has been a good predictor of later ToM ability in typically developing children (25). Although simple forms of ToM are dependent on visual imagery, higher orders depend on verbal thought (26). In particular, the change from natural concepts to social concepts represents a distinct stage in the development of ToM. The use of feeling words such as "happy" and "sad" and desire words such as "want," "like," and "need" begins around 18-24 mo of age, and until $3 \mathrm{y}$ of age, children acquire semantic terms for mental states that include others, learning and using words such as "know," "think," and "pretend" (27-29). By age 4, a child understands that beliefs and desires are private and changeable and do not depend on the external state of reality changing $(4,6)$. ToM is particularly important in pragmatics, i.e. the ability to use language appropriately in social contexts and narrative abilities, such as storytelling. Children with autism, who display deficits in ToM in varying degrees, have limited understanding and infrequent use of mental state terms and have difficulties in understanding idioms and metaphors (30).

Four-year-olds are also able to distinguish between finding out through direct experience and finding out through being told. Although children are poor at distinguishing between different forms of direct experience even at $4 \mathrm{y}$, normal children at around 4 or $5 \mathrm{y}$ of age begin to acknowledge their own prior false beliefs as well as the false beliefs of other people; 5- and 6-y-old children display sophisticated understanding of emotions, having discovered that emotions are based on people's beliefs rather than measures of objective reality (31). 
Developing a full ToM requires the presence of several of the executive functions (EF), such as processes of analysis, inference, deduction, and estimating. Despite a close association between EF and ToM, they are discrete functions (32). Some components of ToM codevelop with EF (33), whereas others develop independently in adults (34). Attaining a particular level of EF is not itself sufficient to yield strong ToM performance (35). In autism, there may be spared or superior executive abilities.

Perspective-taking, one of the essential components of ToM, requires knowledge that one individual has a different perspective than another and thus involves distinguishing between self and others (36). Detaching oneself from one's own perspective is "putting oneself in someone else's shoes," as well as being able to discriminate external manifestations of others' intentions and desires.

Some evidence has emerged that ToM development is strongly affected by nonheritable and social/environmental factors (37-39). Maternal/parental conversational elaboration is a significant predictor of children's ToM performance (40). Appropriate use of personal pronouns "I" and "you" or frequent use of "think" and "know," stimulate children to do better later at ToM tasks (39). Having siblings may also improve children's ToM performance $(41,42)$. The extent to which there is sibling- and extended-family interaction (42) and the child's social behavior (e.g. talk about feeling states and amount of cooperation with siblings) affects the development of ToM in infants (43). ToM appears at substantially different times in different cultures and languages; for example, there are significant differences between Asian and Western cultures (44). The socioeconomic background a child grows up in greatly influences the rate at which its ToM develops (30). Furthermore, the development of ToM may be adversely affected by social deprivation and maltreatment (45); and home-reared children are better than institutionalized children in ToM development (46).

Practically, the whole of childhood, from kindergarten age to the end of secondary school, involves gaining and refining ToM ability. Continuous refinement of the capacity of the individual to gain insights into the minds of others continues throughout adult human life. It is likely that what develops subsequently is the ability to apply ToM findings in a more flexible way and in more complex situations. Individual differences in ToM performance persist through the school years and beyond, into adulthood $(4,6)$.

\section{Measuring ToM in Children}

ToM testing started with the study of autism, and to date, more than 30 experimental tests have been developed for measuring ToM in children (36). Many of these consist in the narration of a brief story followed by questions that require well-developed ToM skills to be correctly answered. The common tests for assessment of ToM ability, false-belief tests, depend on the assumption that one of the most important milestones in ToM development is gaining the ability to recognize that others can have beliefs about the world that are wrong. The classic "false-belief task," developed by psychol- ogists (7) is a story acted out with dolls and props (the original version is German). In the Sally and Anne Test (47), there is a "first-order" task which requires that another person's mental state must be read/understood. Normal children will pass this test by 3-4 y of age. Children with autism typically do not pass; those who do, pass the tests a later age than children without autism. "Second-order" false-belief tasks involve understanding what two people think sequentially, for example, "John thinks what Mary thinks." Normal children will pass second-order tests at around $6 \mathrm{y}$ of age. High-functioning children with autism may also pass these tests, but not before their teen years (48). Ten- and 11-year-old children master first- and second-level theory of mind problems. Although, until recently, most empirical attention was focused on a narrow age range of preschool children [both typically developing children and children with autism spectrum disorder (ASD)] who were tested on a very narrow range of tasks, making it possible that critical phenomena were being missed, we now have third- and fourth-level tests for adolescents and adults (48).

In addition to story tests, there are several nonverbal tests of ToM (49,50), such as Gallagher's Cartoon Task Test (2000) and Zaitchik's False Photograph Test (1990). Tests for the assessment of higher levels of ToM as well as different components of social cognition such as understanding metaphor, sarcasm, and humor have been developed. The most widely used of these advanced-level tests include Happé's Strange Stories Test (1994), Baron-Cohen and O'Riordan's Faux Pas Recognition Test (1999), and Egeth and Kurzban's Meta Photograph Test (2008), each of which uses different cognitive aspects of ToM processing (51-53). For example, another more adult-oriented test, Baron-Cohen's Reading the Mind in the Eyes Test (2002) uses visual tasks that are relatively less demanding in terms of executive abilities (54). Most of these tests are static. Use of more dynamic, behavioral tests, for example, movie clips of acted or naturally occurring social interactions (55) or an online communication game where the speaker's perspective needs to be taken into account (56) may be more sensitive to mindreading deficits in mild and adult cases of ASD. In contrast to these artificial tests, more recent ToM tasks include real-life interactions. Interestingly, successful performance by individuals with ASD in these tests indicates that individuals with ASD are unlikely to have a systematically deficient ToM (57), and comprehensive testing of ToM should therefore consider the multiple components and dimensions that constitute ToM skills (58). All these tests, even the nonverbal ones, require some language skills, and slight changes in the test instructions may improve performance. On the other hand, cultural differences affect the level of performance and children in different countries perform differently, ranging from especially good performance in Australia to poor performance in Japan (36).

\section{Real-Life Consequences of ToM Development and Clinical Conditions With ToM Deficit}

The development of ToM ability has important consequences for children's social communication, interactions, and 
behavior, for example, in conversations, negotiations, games, and friendships, which involve interpersonal sensitivity in real social settings including home, school, and the work environment $(59,60)$. ToM is an essential aspect of spontaneous mental state inference for moral judgment, moral cognition, and moral emotions. Blushing, understanding teasing, and embarrassment are related to a healthy presence of ToM. Feeling trust is dependent on the functional significance of ToM activity (1). Not surprisingly, ToM understanding is of utmost importance in deceptive contexts, such as the ability to mislead people, hide things, conceal information, keep a secret, and lie, and also succeeding in detecting these strategies when others use them; in fact, deliberate deception is one of the earliest signs of ToM development (61). Normal but inefficient ToM may result in self-deception (1). Correct prediction and explanation of others' behavior in terms of ToM categories allows us to manipulate behavior, increasing the likelihood of deceptive or altruistic cooperation, both of which also include diplomacy (36).

ToM fails to develop in individuals with neurodevelopmental disorders, such as autism, and in cases of severely restricted linguistic inputs, e.g. deaf children of nonsigning parents (62). Problems in ToM at different levels and in varying degrees are seen in all autists (63) although it is unclear whether they are due to motivational failure or a cognitive deficit (64). ToM deficits also occur in many other disorders, including schizophrenia (65), bipolar affective disorder (66), mental retardation (67), congenital blindness (68), attention deficit hyperactivity disorder (ADHD) (69), and certain types of language impairment (70). ToM deficits are present in patients with dementia including frontotemporal dementia, Alzheimer's dementia, and other dementing disorders, including amyotrophic lateral sclerosis (71). Acquired (traumatic, nontraumatic, or surgical) injuries to different parts of the brain (particularly frontal and/or right hemisphere lesions) may also cause impairment of ToM (72).

Autism spectrum disorders. ASD is a frequent neurodevelopmental disorder, with a prevalence of 6 per 1000 children (73). It is mainly characterized by poor ToM abilities (3) in connection with problems in pretend play. It is difficult for individuals with ASD to access their own mental states (74), and they demonstrate significant changes over time in ToM (75). Adolescents and adults with ASD, in particular those with normal IQ (high-functioning ASD) can often perform conceptual ToM tasks at various levels of complexity (76). They have been found to perform better when they were motivated to respond adequately (77) and in structured social interactions (78).

Developmental language disorders. Developmental language disorders (DLD), including specific language impairment, can give rise to severe problems in later ToM development as advanced levels of ToM depend on intact language development. Children with DLD display deficits in falsebelief understanding, which persist in adult life (79). Although general grammatical development and vocabulary contribute significantly to ToM reasoning (80), impairment of grammar does not preclude a sound development of ToM, particularly in children with normal comprehension. Cases of patients with severely impaired grammar whose first- and second-order false-belief reasoning is intact have been found (81). However, grammar and ToM are strongly associated over time in children with high functioning ASDs as important predictors of adolescent adaptive functioning (82).

Attention deficit hyperactivity disorder. ADHD is basically an executive dysfunction causing severe problems in social interactions. Given the intricate relationship between EF and ToM development, children with ADHD fail in some tests of ToM and display impairments involving emotion, face and prosody perception, and reduced empathy (69). It is likely that it is their impulsivity and lack of ability to focus attention, and the behavioral problems that these give rise to, that hinder ToM development in children with ADHD (83).

Congenital deafness. Deaf children have problems in ToM development because they have problems accessing conversational interaction, which involves hearing people talk about mental states, a critical source of ToM development for both sighted and blind children. Deaf children of hearing parents, i.e. $96 \%$ of all deaf individuals (84), and deaf children whose parents are nonnative signers, typically do not master sign language until they go to school. They are generally severely delayed in passing false-belief tasks (85). Deaf children with nonsigning parents will experience long-term absence of internal speech and have less opportunity than most to talk about mental states and are less exposed to rich pragmatic and semantic aspects of the language. Deaf children's understanding of emotions may be different; for example, desires may take precedence (86). They show emotional lability. Hence, the majority of deaf children tend to be delayed in acquiring ToM and perform no better than autistic children of the same mental age (62). However, deaf children of deaf parents, i.e. children whose parents are native signers, are not delayed in passing tests based on false-belief tasks (87). Hence, differences in signers and nonsigners, and between early signers and late signers, in relation to ToM development are a further example of the ways becoming proficient in sign language influences deaf children's cognitive and emotional development (88).

Schizophrenia. The ToM deficits displayed by schizophrenics may be caused by their failure to follow their own and other people's mental states and behavior. According to Frith (65), supported empirically by other studies (89), different types of ToM skill impairment account for the different symptom categories in schizophrenia. These include both negative symptoms related to disorders of "willed action" and positive symptoms related to disorders of self-monitoring (delusions and hallucinations), as well as disorganization symptoms related to disorders of monitoring other people's thoughts and intentions. This, however, fails to explain many aspects of schizophrenia, for example, how an impaired ToM in schizophrenia is associated with other aspects of cognition, the fluctuation of impairment with the acuity or chronicity of the schizophrenic disorder, as well as the language mechanisms and social behavior associated with schizophrenics (89).

Congenital blindness. Autism and blindness may coexist in different syndromes. Many blind children display autistic features such as echolalia and stereotypies, restrictions in 
creative symbolic play, confusions in the comprehension and use of personal pronouns, and more formulaic language (90). Recent studies show that congenitally blind people are delayed in performing standard ToM tasks and seem to have difficulty in developing a ToM due to the absence of information provided by joint referential attention and shared focus to an external referent (91), although these early delays may subsequently be overcome via increased ability to learn from what people say about mental states and other compensatory cognitive developments. In typical development, visual information provided by following adults' eye movements, and pointing and producing demonstrative points to guide adults' attention are prerequisites for development of joint and coordinated attention. Congenital blindness limits the infant's experience of observing other humans, a facilitator of ToM development (68). Lacking the experience of having shared or contrasting attitudes toward a visually constructed world causes impoverishment in specific forms of interpersonal experiences and therefore limited reciprocal engagement with other people's relatedness to the world. Congenital blindness prevents a myriad of opportunities for infants to follow other people's lines of gaze, to perceive the objects of their feelings and attitudes, and the directedness of their actions and attitudes, and to grasp alternative meanings in reality and play, and this leads to severe limitations in psychological perspective-taking and social referencing (92). However, it should be noted that absence of visual learning in the infant and child does not change the neural mechanisms for ToM in adulthood (93).

Personality disorders. Many people with personality disorders, particularly schizoid, schizotypal, antisocial $(94,95)$, narcissistic, borderline (96), and paranoid personality disorders (97), as well as children with conduct disorder (98), display some deficits in ToM, such as neglect or a failure to understand that others may have different perspectives differing from their own, although some of these people are known to successfully cheat or manipulate others (including their therapists) (89). Recent studies indicate there are distinctions between the ToM deficits of psychopathic individuals and those of autists; contrary to expectations, people with psychopathy seem to have unimpaired ToM skills reading the "language of the eyes" despite their lack of concern about the effects of violence on other people $(8,97)$.

The three principal theoretical accounts of the development of ToM mechanisms are the Theory Theory, Simulation Theory, and Modularity Theory (36). The explanation of ToM in terms of Theory Theory depends on the distinction between our beliefs and concepts about the physical world, which may be called "primary representations," and our beliefs about other people's mental states (such as their beliefs and desires) called "second-order representations" or "meta-representations" (53). Simulation Theory implies imagining oneself in the other's position in a hypothetical scenario to make a decision about what the other person will do (99). However, a closer look at the mechanisms of simulation and representation reveals an unclear distinction between these two theoretical accounts of ToM, rendering the current application of these theories redundant (100). ToM is a cognitively demand- ing, effortful activity even for adults (101); it does not occur automatically (102). People tend to interpret behavior in terms of the actors' mental states only as a response to a real-life task and to the extent that they have the cognitive resources to do so (103). Even in normal people, accuracy is far from perfect (104). People cannot simply assume that others think and feel exactly as they do. There have to be additional processes of adjustment for perceived differences between self and others (105). For example, when making judgments about the mental states of others, interference from self-perspective must be resisted $(106,107)$. It is possible that there are two types of mentalizing. Simulation-based judgments, which are heavily influenced by the salience of the individual's own beliefs, are less flexible but cognitively efficient, and appear earlier than the rule-based mentalizing judgments, which are flexible responses to more cognitively demanding tasks (108).

Modularity Theory assumes a specialized system of neural architecture that is dedicated to ToM processing by which a specific kind of input (information about behavior) is obtained, and a particular output (description of mental states) is produced (21). The neurobiological ontogeny of ToM depends on brain maturation and development as well as the changes in brain activity that occurs in the neural substrates during childhood and adolescence. In fact, the neural correlates of ToM should be sought in the developing brain circuitry shaped by interpersonal interactions. New imaging results have shown the cooperative nature of several distinct neural networks for the different stages and components of ToM in terms of changing functional connectivity by age (109). It is likely that the interaction between these regions and their wiring under social influences is critical for intact ToM development, effectively forming a network of interconnected subspecialized regions, which can be thought of as the "social brain" (110-112).

Although the findings are heterogeneous, recent neuroimaging studies demonstrate a network that links the medial prefrontal cortex (MPFC) and temporal cortex including the temporal poles and temporoparietal junction, and the precuneus as the neural substrate of intuitive mentalizing (113). Activations in the ventral MPFC may provide the basis for our "emotional bond" with other people's emotions (114). The superior dorsal MPFC region is activated when thinking about others' dissimilar mental states (115). The temporoparietal junction, consisting mainly of the superior temporal sulcus and inferior parietal lobule, is an essential area in belief attribution (116). Other regions of the brain which are of interest in relation to other aspects of ToM mechanisms include the amygdala, orbitofrontal cortex, and ventral striatum, all of which play a role in the modulation of complex reward mechanisms, the anterior and posterior cingulate cortices, and the paracingulate cortex, which are vital to the integration of cognition and affect (113). Magnetoencephalography studies highlight the importance of the study of the functional connectivity between areas of ToM and areas of the default mode network, which are active during passive resting states of the brain in relation to ToM mechanisms (117).

Some recently discovered neurons in the cerebral cortex are hypothesized to play a role in the simulation mechanism of 
ToM functions. These functionally specialized neurons, known as mirror neurons, are present in different cortical areas. The ones in the parietofrontal network are visuomotor neurons, which discharge both when performing and observing a goal-directed action. The ones in the insula and anterior cingulate mediate the understanding of other people's emotions and are activated when disgust or pain are experienced, and when one sees others experiencing these emotions (118). Although evidence from functional MRI, transcranial magnetic stimulation, and an electroencephalographic component called the mu rhythm suggests mirror neurons are dysfunctional in individuals with ASD (119), recent studies have reported contrary findings (120). A possible role in the neural mechanism of intuition and autism are proposed for the spindle-shaped or von Economo neurons, a special type of neuron with specific anatomical and physiological properties. Most prominent in the rostral anterior cingulate cortex (121), they are only found in humans and great apes.

The study of ToM is part of the larger field of social neuroscience, which encompasses the empirical study of the neural mechanisms underlying social, cognitive, and affective processes, seen in terms of their ontogenetic and phylogenetic development (122). The general cognitive processes involved in perception, language, memory, and attention are synthesized in the brain as processes that are specific to social interaction. The functional organization of the human brain involves transformations that occur within an interactive cultural context that provides "extracerebral links" to socially shared and culturally transmitted meanings (123) and simultaneously produces modification of relevant inborn biological mechanisms (124). As the result of the protracted postnatal wiring of the brain under social influences, which include parenting, school, and the other important environmental determinants of childhood and adolescence, social functions progressively gain control over biological mechanisms. Hence, the study of connections between fundamental neurophysiological mechanisms and highly complex social behavior, such as ToM, via advanced techniques of neuroimaging and genetic studies, is a source of data that will enable us to better understand the respective roles of innate predisposition and cultural learning in human life (122). Studies in the social, cognitive, and affective sciences currently seem to be the most fruitful approach to successfully contrasting both the mindbody dualism inherent in some psychological thinking and those theories of neuroscience that have been influenced by biological reductionism.

Acknowledgments. I express my gratitude to the editor and the anonymous reviewer for their valuable comments and criticism, to Susan Finnel for language editing, and to Charles Njiokiktijien for his encouragement and support.

\section{REFERENCES}

1. Wellman HM, Miller JG 2008 Including deontic reasoning as fundamental to theory of mind. Hum Dev 51:105-135

2. Premack D, Woodruff G 1978 Does the chimpanzee have a theory of mind? Behav Brain Sci 1:515-526

3. Baron-Cohen S 1995 Mindblindness: An Essay on Autism and Theory of Mind The MIT Press/Bradford, Cambridge, pp 1-7
4. Frith U, Frith CD 2003 Development and neurophysiology of mentalizing. Philos Trans R Soc Lond B Biol Sci 358:459-473

5. Call J, Tomasello M 2008 Does the chimpanzee have a theory of mind? 30 years later. Trends Cogn Sci 12:187-192

6. Brüne M, Brüne-Cohrs U 2006 Theory of mind-evolution, ontogeny, brain mechanisms and psychopathology. Neurosci Biobehav Rev 30:437-455

7. Wimmer H, Perner J 1983 Beliefs about beliefs: representation and constraining function of wrong beliefs in young children's understanding of deception. Cognition 13:103-128

8. Blair RJR 2008 Fine cuts of empathy and the amygdala: dissociable deficits in psychopathy and autism. Q J Exp Psychol 61:157-170

9. Vygotsky LS 1929 The problem of the cultural development of the child. J Genet Psychol 36:415-432

10. Teufel C, Fletcher PC, Davis G 2010 Seeing other minds: attributed mental states influence perception. Trends Cogn Sci 14:376-382

11. Baron-Cohen S, Cross P 1992 Reading the eyes: evidence for the role of perception in the development of a theory of mind. Mind Lang 7:172-186

12. Farroni T, Csibra G, Simion F, Johnson MH 2002 Eye contact detection in humans from birth. Proc Natl Acad Sci USA 99:9602-9605

13. Vecera SP, Johnson MH 1995 Gaze detection and the cortical processing of faces: evidence from infants and adults. Vis Cogn 2:59-87

14. Doherty MJ, Anderson JR 1999 A new look at gaze: preschool children's understanding of eye-direction. Cogn Dev 14:549-571

15. Scaife M, Bruner JS 1975 The capacity for joint visual attention in the infant. Nature 253:265-266

16. Camaioni L, Perucchini P, Bellagamba F, Colonnesi C 2004 The role of declarative pointing in developing a theory of mind. Infancy 5:291-308

17. Onishi KH, Baillargeon R 2005 Do 15-month-old infants understand false beliefs? Science 308:255-258

18. Surian L, Caldi S, Sperber D 2007 Attribution of beliefs by 13-month-old infants. Psychol Sci 18:580-586

19. Connolly JA, Doyle AB 1984 Relation of social fantasy play to social competence in preschoolers. Dev Psychol 20:797-806

20. Lewis V, Boucher J 1988 Spontaneous, instructed and elicited play in relatively able autistic children. Br J Dev Psychol 6:325-339

21. Leslie AM, Freidman O, German TP 2004 Core mechanisms in "theory of mind." Trends Cogn Sci 8:528-533

22. Nelson K, Fivush R 2004 The emergence of autobiographical memory: a social cultural developmental theory. Psychol Rev 111:486-511

23. Rosenbaum RS, Stuss DT, Levine B, Tulving E 2007 Theory of mind is independent of episodic memory. Science 318:1257

24. Nielsen M, Dissanayake C 2004 Pretend play, mirror self-recognition and imitation: a longitudinal investigation through the second year. Infant Behav Dey 27:342-365

25. Farrar MJ, Maag L 2002 Early language development and the emergence of a theory of mind. First Lang 22:197-213

26. Astington JW, Jenkins JM 1999 A longitudinal study of the relation between language and theory of mind development. Dev Psychol 35:1311-1320

27. Wellman HM, Harris PL, Banerjee M, Sinclair A 1995 Early understanding of emotion: evidence from natural language. Cogn Emotion 9:117-149

28. Jenkins JM, Turrell SL, Kogushi Y, Lollis S, Hildy SR 2003 A longitudinal investigation of the dynamics of mental state talk in families. Child Dev 74:905920

29. Knüppel A, Steensgaard R, de López KJ 2007 Mental state talk by Danish preschool children. In: Merete Anderssen M, Westergaard M (eds) Papers from the Language Acquisition Workshop, SCL 2006, Nordlyd 34.3:110-130

30. Tager-Flusberg H 1999 A psychological approach to understanding the social and language impairments in autism. Int Rev Psychiatry 11:325-334

31. Rieffe C, Terwogt MM, Cowan R 2005 Children's understanding of mental states as causes of emotions. Infant Child Dev 14:259-272

32. Fine C, Lumsden J, Blair RJ 2001 Dissociation between 'theory of mind' and executive functions in a patient with early left amygdala damage. Brain 124:287298

33. Carlson SM, Mandell DJ, Williams L 2004 Executive function and theory of mind: stability and prediction from ages 2 to 3. Dev Psychol 40:1105-1122

34. Qureshi AW, Apperly IA, Samson D 2010 Executive function is necessary for perspective selection, not Level-1 visual perspective calculation: evidence from a dual-task study of adults. Cognition 117:230-236

35. Hughes C, Ensor R 2007 Executive function and theory of mind: predictive relations from age 2 to 4 . Dev Psychol 43:1447-1459

36. Doherty MJ 2008 Theory of Mind: How Children Understand Others' Thoughts and Feelings. Psychology Press, New York, pp 1-245

37. Hughes C, Jaffee SR, Happé F, Taylor A, Caspi A, Moffitt TE 2005 Origins of individual differences in theory of mind: from nature to nurture? Child Dev $76: 356-370$

38. Liu D, Wellman HM, Tardif T, Sabbagh MA 2008 Theory of mind development in Chinese children: a meta-analysis of false-belief understanding across languages and cultures. Dev Psychol 44:523-531

39. Meins E, Fernyhough C, Wainwright R, Das Gupta M, Fradley E, Tuckey M 2002 Maternal mind-mindedness and attachment security as predictors of theory of mind understanding. Child Dev 73:1715-1726

40. Ontai LL, Thompson RA 2008 Attachment, parent-child discourse and theory-ofmind development. Soc Dev 17:47-60

41. McAlister A, Peterson C 2007 A longitudinal study of child siblings and theory of mind development. Cogn Dev 22:258-270 
42. Lewis C, Freeman NH, Kyriakidou C, Maridaki-Kassotaki K, Berridge DM 1996 Social influences on false belief access: specific sibling influences or general apprentice? Child Dev 67:2930-2947

43. Watson AC, Nixon CL, Wilson A, Capage L 1999 Social interaction skills and theory of mind in young children. Dev Psychol 35:386-391

44. Lu H, Su J, Wang Q 2008 Talking about others facilitates theory of mind in Chinese preschoolers. Dev Psychol 44:1726-1736

45. Pears KC, Fisher PA 2005 Emotion understanding and theory of mind among maltreated children in foster care: evidence of deficits. Dev Psychopathol 17:47-65

46. Yagmurlu B, Berument SK, Celimli S 2005 The role of institution and home contexts in theory of mind development. J Appl Dev Psychol 26:521-537

47. Baron-Cohen S, Leslie AM, Frith U 1986 Mechanical, behavioural and intentional understanding of picture stories in autistic children. Br J Dev Psychol 4:113-125

48. Liddle B, Nettle D 2006 Higher-order theory of mind and social competence in school-age children. J Cult Evol Psychol 4:231-244

49. Gallagher HL, Happé F, Brunswick N, Fletcher PC, Frith U, Frith CD 2000 Reading the mind in cartoons and stories: an fMRI study of 'theory of mind' in verbal and nonverbal tasks. Neuropsychologia 38:11-21

50. Zaitchik D 1990 When representations conflict with reality: the preschooler's problem with false beliefs and "false" photographs. Cognition 35:41-68

51. Happé FG 1994 An advanced test of theory of mind: understanding of story characters' thoughts and feelings by able autistic, mentally handicapped and normal children and adults. J Autism Dev Disord 24:129-154

52. Baron-Cohen S, O'Riordan M, Jones R, Stone VE, Plaisted K 1999 A new test of social sensitivity: detection of faux pas in normal children and children with Asperger syndrome. J Autism Dev Disord 29:407-418

53. Egeth M, Kurzban R 2009 Representing metarepresentations: is there theory of mind-specific cognition? Conscious Cogn 18:244-254

54. Baron-Cohen S, Wheelwright S, Hill J, Raste Y, Plumb I 2001 The "Reading the Mind in the Eyes" Test revised version: a study with normal adults, and adults with Asperger syndrome or high-functioning autism. J Child Psychol Psychiatry 42:241-251

55. Roeyers H, Buysse A, Ponnet K, Pichal B 2001 Advancing advanced mind-reading tests: empathic accuracy in adults with a pervasive developmental disorder. J Child Psychol Psychiatry 42:271-278

56. Keysar B, Lin S, Barr DJ 2003 Limits on theory of mind use in adults. Cognition 89:25-41

57. Begeer S, Malle BF, Nieuwland MS, Keysar B 2010 Using Theory of Mind to represent and take part in social interactions: comparing individuals with highfunctioning autism and typically developing controls. Eur J Dev Psychol 7:104122

58. Malle BF 2008 The fundamental tools, and possibly universals, of human social cognition. In: Sorrentino R, Yamaguchi S (eds) Handbook of Motivation and Cognition Across Cultures. Elsevier/Academic Press, London, pp 267-296

59. Cutting AL, Dunn J 1999 Theory of mind, emotion understanding, language, and family background: individual differences and interrelations. Child Dev 70:853865

60. Jenkins JM, Astington JW 1996 Cognitive factors and family structure associated with theory of mind development in young children. Dev Psychol 32:70-78

61. Spence SA, Hunter MD, Farrow TF, Green RD, Leung DH, Hughes CJ, Ganesan V 2004 Deception: evidence from neuroimaging. Philos Trans R Soc Lond B Biol Sci 359:1755-1762

62. Peterson CC, Siegal M 2000 Insights into theory of mind from deafness and autism Mind Lang 15:123-145

63. Happé F, Frith U 1996 The neuropsychology of autism. Brain 119:1377-1400

64. Verbeke E, Peeters W, Kerkhof I, Bijttebier P, Steyaert J, Wagemans J 2005 Lack of motivation to share intentions: primary deficit in autism? Behav Brain Sci 28:718-719

65. Frith CD 1992 The Cognitive Neuropsychology of Schizophrenia. Lawrence Erlbaum Associates, Hove, UK, pp 124-126

66. Bora E, Vahip S, Gonul AS, Akdeniz F, Alkan M, Ogut M, Eryavuz A 2005 Evidence for theory of mind deficits in euthymic patients with bipolar disorder. Acta Psychiatr Scand 112:110-116

67. Capps L, Kehres J, Sigman M 1998 Conversational abilities among children with autism and children with developmental delays. Autism 2:325-344

68. Hobson RP, Lee A, Brown R 1999 Autism and congenital blindness. J Autism Dev Disord 29:45-56

69. Uekermann J, Kraemer M, Abdel-Hamid M, Schimmelmann BG, Hebebrand J, Daum I, Wiltfang J, Kis B 2010 Social cognition in attention-deficit hyperactivity disorder (ADHD). Neurosci Biobehav Rev 34:734-743

70. Gillott A, Furniss F, Walter A 2004 Theory of mind ability in children with specific language impairment. Child Lang Teach Ther 20:1-11

71. Modinos G, Obiols JE, Pousa E, Vicens J 2009 Theory of Mind in different dementia profiles. J Neuropsychiatry Clin Neurosci 21:100-101

72. Martín-Rodríguez JF, León-Carrión J 2010 Theory of mind deficits in patients with acquired brain injury: a quantitative review. Neuropsychologia 48:1181-1191

73. Chakrabarti S, Fombonne E 2005 Pervasive developmental disorders in preschool children: confirmation of high prevalence. Am J Psychiatry 162:1133-1141

74. Varga S 2010 Pretence, social cognition and self-knowledge in autism. Psychopathology 44:46-52

75. Pellicano E 2010 The development of core cognitive skills in autism: a 3-year prospective study. Child Dev 81:1400-1416

76. Dahlgren SO, Trillingsgaard A 1996 theory of mind in non-retarded children with autism and Asperger's Syndrome: a research note. J Child Psychol Psychiatry 37:759-763
77. Begeer S, Rieffe C, Terwogt MM, Stockmann L 2003 Theory of mind-based action in children from the autism spectrum. J Autism Dev Disord 33:479-487

78. Ponnet K, Buysse A, Roeyers H, De Corte K 2005 Empathic accuracy in adults with a pervasive developmental disorder during an unstructured conversation with a typically developing stranger. J Autism Dev Disord 35:585-600

79. Redmond SM, Rice ML 1998 The socioemotional behaviors of children with SLI: social adaptation or social deviance? J Speech Lang Hear Res 41:688-700

80. Farrar MJ, Johnson B, Tompkins V, Easters M, Zilisi-Medus A, Benigno JP 2009 Language and theory of mind in preschool children with specific language impairment. J Commun Disord 42:428-441

81. Apperly IA, Samson D, Carroll N, Hussain S, Humphreys G 2006 Intact first- and second-order false belief reasoning in a patient with severely impaired grammar. Soc Neurosci 1:334-348

82. Paynter J, Peterson C 2010 Language and ToM development in autism versus Asperger syndrome: contrasting influences of syntactic versus lexical/semantic maturity. Res Autism Spectr Disord 4:377-385

83. Perner J, Kain W, Barchfeld P 2002 Executive control and higher-order theory of mind in children at risk of ADHD. Infant Child Dev 11:141-158

84. Kushalnagar P, Mathur G, Moreland CJ, Napoli DJ, Osterling W, Padden C, Rathmann C 2010 Infants and children with hearing loss need early language access. J Clin Ethics 21:143-154

85. Schick B, de Villiers P, de Villiers J, Hoffmeister R 2007 Language and theory of mind: a study of deaf children. Child Dev 78:376-396

86. Rieffe C, Terwogt MM 2000 Deaf children's understanding of emotions: desires take precedence. J Child Psychol Psychiatry 41:601-608

87. de Villiers PA 2005 The role of language in Theory-of-Mind development: what deaf children tell us. In: Astington JW, Baird JA (eds) Why Language Matters for Theory of Mind. Oxford University Press, Oxford, pp 266-297

88. Woolfe T, Want SC, Siegal M 2003 Siblings and theory of mind in deaf native signing children. J Deaf Stud Deaf Educ 8:340-347

89. Brüne M 2005 "Theory of mind" in schizophrenia: a review of the literature. Schizophr Bull 31:21-42

90. Pérez-Pereira M 1994 Imitations, repetitions, routines, and the child's analysis of language: insights from the blind. J Child Lang 21:317-337

91. Dale N, Salt A 2008 Social identity, autism and visual impairment (VI) in the early years. Br J Vis Impairment 26:135-146

92. Hobson RP, Bishop M 2003 The pathogenesis of autism: insights from congenital blindness. Philos Trans R Soc Lond B Biol Sci 358:335-344

93. Bedny M, Pascual-Leone A, Saxe RR 2009 Growing up blind does not change the neural bases of Theory of Mind. Proc Natl Acad Sci USA 106:11312-11317

94. Richell RA, Mitchell DV, Newman C, Leonard A, Baron-Cohen S, Blair RJ 2003 Theory of mind and psychopathy: can psychopathic individuals read the "language of the eyes'? Neuropsychologia 41:523-526

95. Dolan M, Fullam R 2004 Theory of mind and mentalizing ability in antisocia personality disorders with and without psychopathy. Psychol Med 34:1093-1102

96. Fonagy P 1989 On tolerating mental states: theory of mind in borderline personality. Bull Anna Freud Centre 12:91-115

97. Ang GK, Pridmore S 2009 Theory of mind and psychiatry: an introduction. Australas Psychiatry 17:117-122

98. Dodge KA 1993 Social-cognitive mechanisms in the development of conduct disorder and depression. Annu Rev Psychol 44:559-584

99. Apperly IA 2008 Beyond Simulation-Theory and Theory-Theory: why socia cognitive neuroscience should use its own concepts to study "theory of mind." Cognition 107:266-283

100. Apperly IA, Butterfill SA 2009 Do humans have two systems to track beliefs and belief-like states? Psychol Rev 116:953-970

101. Apperly IA, Samson D, Humphreys GW 2009 Studies of adults can inform accounts of theory of mind development. Dev Psychol 45:190-201

102. Lin S, Keysar B, Epley N 2010 Reflexively mindblind: using theory of mind to interpret behavior requires effortful attention. J Exp Soc Psychol 46:551-556

103. Back E, Apperly IA 2010 Two sources of evidence on the non-automaticity of true and false belief ascription. Cognition 115:54-70

104. Klein KJK, Hodges SD 2001 Gender differences, motivation, and empathic accuracy: when it pays to understand. Pers Soc Psychol Bull 27:720-730

105. Hamilton AF 2009 Goals, intentions and mental states: challenges for theories of autism. J Child Psychol Psychiatry 50:881-892

106. Decety J, Grezes J 2006 The power of simulation: imagining one's own and other's behaviour. Brain Res 1079:4-14

107. Samson D, Apperly IA, Humphreys GW 2007 Error analyses reveal contrasting deficits in "theory of mind": neuropsychological evidence from a 3-option false belief task. Neuropsychologia 45:2561-2569

108. Mitchell P, Currie G, Ziegler F 2009 Two routes to perspective: simulation and rule-use as approaches to mentalizing. Br J Dev Psychol 27:513-543

109. Burnett S, Blakemore SJ 2009 Functional connectivity during a social emotion task in adolescents and adults. Eur J Neurosci 29:1294-1301

110. Brothers L 1990 The social brain: a project for integrating primate behavior and neurophysiology in a new domain. Concepts Neurosci 1:27-51

111. Lieberman MD 2010 Social cognitive neuroscience. In: Fiske ST, Gilbert DT, Lindzey G (eds) Handbook of Social Psychology, 5th ed. John Wiley \& Sons, Inc. Hoboken, New Jersey, pp 143-193

112. Uddin LQ, Iacoboni M, Lange C, Keenan JP 2007 The self and social cognition: the role of cortical midline structures and mirror neurons. Trends Cogn Sci 11:153-157

113. Carrington SJ, Bailey AJ 2009 Are there theory of mind regions in the brain? A review of the neuroimaging literature. Hum Brain Mapp 30:2313-2335 
114. Schulte-Ruther M, Greimel E, Markowitsch HJ, Kamp-Becker I, Remschmidt H, Fink GR, Piefke M 2010 Dysfunctions in brain networks supporting empathy: an fMRI study in adults with autism spectrum disorders. Soc Neurosci 13:1-21

115. Dumontheil I, Küster O, Apperly IA, Blakemore SJ 2010 Taking perspective into account in a communicative task. Neuroimage 52:1574-1583

116. Zaitchik D, Walker C, Miller S, LaViolette P, Feczko E, Dickerson BC 2010 Mental state attribution and the temporoparietal junction: an fMRI study comparing belief, emotion, and perception. Neuropsychologia 48:2528-2536

117. Assaf M, Jagannathan K, Calhoun VD, Miller L, Stevens MC, Sahl R, O'Boyle JG, Schultz RT, Pearlson GD 2010 Abnormal functional connectivity of default mode sub-networks in autism spectrum disorder patients. Neuroimage 53:247256
118. Rizzolatti G, Fabbri-Destro M 2008 The mirror system and its role in social cognition. Curr Opin Neurobiol 18:179-184

119. Perkins T, Stokes M, McGillivray J, Bittar R 2010 Mirror neuron dysfunction in autism spectrum disorders. J Clin Neurosci 17:1239-1243

120. Press C, Richardson D, Bird G 2010 Intact imitation of emotional facial actions in autism spectrum conditions. Neuropsychologia 48:3291-3297

121. Allman JM, Watson KK, Tetreault NA, Hakeem AY 2005 Intuition and autism: a possible role for Von Economo neurons. Trends Cogn Sci 9:367-373

122. Blakemore SJ, Winston J, Frith U 2004 Social cognitive neuroscience: where are we heading? Trends Cogn Sci 8:216-222

123. Akhutina TV 2003 L.S. Vygotsky and A.R. Luria: foundations of neuropsychology. J Russ East Eur Psychol 41:159-190

124. Vygotsky LS 1965 Psychology and localization of functions. Neuropsychologia 3:381-386 